\title{
Folk Sports Development under the Context of Ceramic Culture
}

\author{
Jin Ying ${ }^{1,}$ \\ ${ }^{1}$ Department of Military and Sports, Jingdezhen Ceramic Institute \\ Jingdezhen, Jiangxi Province, China
}

\section{Keywords: Ceramic culture; Folk sports}

\begin{abstract}
Since the reform and opening up, the western sports culture has become popular, many characteristics of the local folk sports culture is disappearing. As China's economic strength become strong, it is very important to protect and develop the traditional folk culture with traditional culture characteristics. This paper expounds the symbiosis of ceramic culture and folk sports culture, it is pointed out that Jingdezhen should rely on three platforms such as "Porcelain Fair", "Ceramic Cultural Tourism", and "Ceramic Art Culture", to improve the influence of folk sports culture, and promote the protection and development of folk sports.
\end{abstract}

\section{Introduction}

With the rapid development of global globalization trend, the global allocation of resources has brought development opportunities to various countries and regions, and promote the development of the world economy. However, economic globalization has brought great impact to the traditional sports culture ecology of various countries and regions, and the cultural heritage and its living environment are seriously threatened. As a foreign species of western sports culture, showing a strong vitality, sweeping the Chinese land in a lightning speed, the traditional sports culture ecology completely lost balance, Western sports culture become popular. The mainstream ideology culture in each region is also "devouring" and "digesting" the small folk culture, so that the folk culture lose the ecological environment for the existence. Jingdezhen, the part of Pianhuigan northeast mountain corner also experience this folk culture catastrophe, folk sports culture with cultural characteristics is slowly dying, or even move to die. "House leakage coupled with rain", after the destruction of kaolin resources, but faced with the destruction of traditional cultural and ecological resources. Ceramic culture legislation of the city's strategy break through the double dilemma, ushered in the "bright future". The rise of ceramic culture tourism industry, ceramic culture creative industries and others greatly promote the development of Jingdezhen. Thought determines the development of culture, culture affects the pattern of industry. The strongness of ceramic culture leads to the unity of ceramic culture industry, leading to the lack of thickness and depth of urban development. In recent decades, scholars are aware of the importance of national and regional cultural development. Protecting and developing folk sports culture, cultivating Jingdezhen cultural and ecological environment, seems to have practical significance.

\section{Symbiosis of Ceramic Culture and Folk Sports Culture}

A generation master Qian $\mathrm{Mu}$ said that "for the nationally traditional culture, it was cultivated by their own national transmission during several hundreds of years". It can be seen that the cultural characteristics of a region was formed by its geographical location of the climate, temperature and other natural factors and the people who live in the region using blood and flesh to cultivate it during thousands of years. Regional folk culture get mutual integration, showing the total characteristics of traditional Chinese culture. Ceramic culture as the mainstream of Jingdezhen cultural form has existed for thousands of years, the prosperity of ceramic culture gave birth to the formation of a large number of other non-mainstream culture, and a variety of cultures appear by taking ceramic culture as a platform. With the accumulation of time, it formed the cultural circle including folk sports culture and other culture treating ceramic culture as the core. 


\section{"Sacrifice God of Kiln" is the Integration of Ceramic Culture and Folk Sports Culture}

Due to the limitations of the times, the control of fire temperature are also very dependent on experience for people. In order to pray for the harvest, people will hope to pin in the gods bless, so there will be a memorial ceremony for god of kiln. In order to express the joy of harvest and thanks to the gods, before and after of "sacrifice god of kiln", to hold a variety of folk activities. The people from different region in order to see the grand occasion, gathered from all directions together. The local kiln community also shut down business, the flag with the kiln marks will get together. Various types of folk activities around the performance teams were invited to come, appeared in the "sacrifice god of kiln" scene. At this time, the place is full of people, flags fluttering, music singing, firecrackers releasing, it is truly lively. The text has a stilts, jumping clam shell, singing and so on, martial arts have dragon dance, lion dance, dragon boat and so on. From the above description, we can see that the kiln is the integration of the ceramic culture and folk sports culture, it is difficult to have their own independence. Sacrifice god of kiln activity is also a traditional cultural folk activities with high value, should fully tap the value of this folk activities in the sacrifice god of kiln

\section{The Performance of Folk Sports Culture in Ancient Ceramic Art Works}

Art originated in life, several generations of potters or ceramic artists deeply rooted the heart of the folk sports image heart into the soil, with the kiln fire quenching to retain the masterpiece. The types and the number on the folk sports culture image of the application in ceramic works have many dynasties. The forms of ancient ceramic art in the folk sports and cultural elements is very rich, the main parts are martial arts Cuju, chess, polo, hammer, archery, wrestling, and other folk sports and cultural factors. The most typical work is undoubtedly the Doucaiyingxi picture cup from Ming Dynasty, the picture of the cup vividly describes the cute and happy image that four children paly a kite. There are collections of the Henan Provincial Museum of the Song Dynasty green glaze phase pottery figurines, pottery figurines image lively showed the wrestling scene. Children image is lively and lovely. Whether it is the Song Dynasty Sumo pottery figurines, or Ming Chenghua baby show cup, all reflect the folk sports culture have the impact on ceramic culture and art.

\section{The Development of Folk Sports Culture under the Ceramic Culture}

\section{Rely on the "Porcelain Fair" platform to carry out local folk sports and cultural} performances and competition ceremony. Since 2004, the 12 consecutive years of porcelain fairs have showed the development process of ceramic culture industry. The impact and role of porcelain fair is beyond reproach, but as the time goes on, the development of porcelain fair gradually revealed the weaknesses of lack of potential. From the beginning of a trading platform, it has been far from being able to meet the needs of the development of ceramic culture industry. Porcelain fair should be a grand festival, should become the platform to show the charm of Jingdezhen city culture. Such a request, ceramic culture, of course, is stretched and hardwood, and local folk sports culture protection and development is particularly important. Jingdezhen is located in $\mathrm{Wu} \mathrm{Chu}$ cultural blend area, folk sports and cultural heritage is very rich. During the 2008 Beijing Olympic Games, Beijing held a national concert, Taijiquan competition performances, temple fairs and other national characteristics of activities, greatly added the charm of the 2008 Beijing Olympic Games. Ancient "Sacrifice God of Kiln" activities also gave us such a revelation. During the porcelain fair, the folk sports culture performances and competitions with the local cultural characteristics should be fully showed, to increase porcelain fair's cultural depth and thickness, thereby enhancing the image of Jingdezhen city culture. From the aesthetic point of view, the dynamic folk sports activities and static ceramic culture can complement each other, then they can ease visual fatigue of the guests to enjoy the different beauty. Only three-dimensionally develop "porcelain Fair" and rich "porcelain fair" content, can we enhance the attraction of "porcelain fair", attracting guests from all directions to come to Jingdezhen. 
Rely on ceramic culture tourism industry to develop local folk sports activities. With the development of society, people's tourism needs continue to be expanded, the requirements for tourism products become more, pay more attention to spiritual culture and other three-dimensional feeling. Tourism products gradually transfer from the natural sightseeing tour to cultural appreciation and aesthetic with the characteristics, active participation in recreational activities, and other multi-level and deep-seated development, taking multi-culture as the carrier of tourism products, favored by more and more tourists. Therefore, we should rely on folk sports culture with the characteristics, and sum up the successful experience of other small and medium-sized city culture development, make the cultural connotation of folk culture through the ceramic culture industry development process. At present, Jingdezhen ceramic culture tourism products cultural elements lack of the level, folk sports and cultural elements have great potential development. Relying on the existing ceramic culture tourism products, such as the National Ancient Kiln Folklore Expo Area, Huang Yao Ceramic Expo Area and other tourist attractions, fully develop and use local folk sports culture, integrate the ceramic culture and folk sports culture, to create a diversified culture three-dimensional cultural tourism products. So that visitors enjoy the static natural scenery, while experiencing the dynamic folk sports and cultural activities with Jingdezhen local customs, so that visitors get a multi-directional sensory enjoyment.

Rely on ceramic art works to enhance the impact of folk sports activitiesWuyuan fully integrated the exorcist dance culture regarded as "living fossils of classical dance in China" and natural cultural tourism landscape advantages, to create the exorcist dance tourism products, favored by domestic and foreign tourists. "Wuyuan Exorcist" folk sports culture development is a model of Jiangxi Province and even the national folk sports culture development, not only promoted the protection and development of Wuyuan local folk sports activities exorcism dance, but also promoted the development of Wuyuan leisure tourism industry. In addition, the development of Wuyuan mask industry is the embodiment of exorcist dance culture and creative industry, when promoting the economic development, greatly enhance the national influence "Wuyuan Exorcist" culture, enhance charm of Wuyuan as a tourist city. Jingdezhen should fully tap the folk sports activities with local characteristics, use ceramic culture to develop ceramic art works of the folk sports with local characteristics to enhance the impact of Jingdezhen folk sports and cultural activities.

\section{Conclusion}

Cultural strength is an important factor for the city's comprehensive strength, to achieve the great rejuvenation of the Chinese nation, it is inseparable from the excellent tradition of cultural heritage and development. China has vast land and rich cultural heritage. Each region should protect and develop the typical local folk culture, maintain the sustainable development of regional cultural ecology. They should deepen awareness of the ceramic culture and folk traditional sports culture, make full use of ceramic culture, take the ceramic culture and creative industry express, protect and develop Jingdezhen local folk sports culture, cultivate and build a ceramic culture as the core, including folk sports culture and other cultural ecology, to achieve a multi-cultural win-win situation.

\section{Acknowledgments}

Fund Project: Jiangxi Provincial Sports Bureau project "The Correlation Study of Youth Lifestyle and Physical Health for 16-20 years old Teenage" (No. 2015030)

\section{References}

[1] Ren Fang. Study on the interactive development of national traditional sports culture industry and tourism industry [J]. Journal of Hebei University of Economics and Business (General Edition), 2010, 10 (2) 
[2] Gong Xunlei. The status quo analysis of Jingdezhen ceramic art and sports elements [J]. Modern Commerce Industry, 2015, 1

[3] He Yuning, Qiu Qilin. Thinking about integration development of Jingdezhen ceramic culture tourism and ceramic creative industry [J]. China Ceramic Industry, 2015, 10

[4] Wang Junqi. The main content and folk culture characteristics of Jiangxi "Exorcism dance" [J]. Fitness Club, 2009, 6

Author: Jin Ying (1982.12-), Master, female, lecturer, Xi'an, Shaanxi, Sports and Military Teaching Department, Jingdezhen Ceramic Institute, research direction: sports humanities sociology. 